\title{
Analysis and Evaluation of Microbial Contamination on Raw Beef in Supermarkets in Phnom Penh, Cambodia
}

\author{
Sarin Neang*, Vouchsim Kong, Rithy Chrun, Borarin Buntong, Kuyhor Te and Vichet Chep \\ Royal University of Agriculture, P.O. Box 2696, Phnom Penh, Cambodia \\ *Corresponding author's e-mail: neangsarin@gmail.com
}

\begin{abstract}
Raw beef is a food product that contains variety of proteins that provide good energy and other nutrients for supporting human health. However, this kind of meat is very easy to be spoiled by microorganism, which seriously affects the consumer's health. In addition, in most case, raw beef is popularly consumed raw or lightly cooked, so the level of microbial contamination is high. Interestingly, samples of raw beefs from three supermarkets were taken to be analyzed and evaluated in this study. This study was designed to (i) determine the presence of foodborne pathogens in raw beef; (ii) compare the prevalence of microbial contamination among the three supermarkets; and (iii) evaluate the sanitary quality of raw beef products. Also, six kind of microorganisms including Total Plate Count, Total Coliform and Fecal Coliform, which represented sanitary quality; and E. coli, S. aureus, and B.cereus, which determined the presence of foodborne pathogens, were analyzed. The results showed that there were no significant differences in Total Plate Counts, Total Coliform and Fecal coliform in the samples taken from the three supermarkets in Phnom Penh city, and they were found in unacceptable numbers in the raw beef products. However, the prevalence of foodborne pathogens including E. coli, S. aureus and $B$. cereus were found in acceptable numbers. Furthermore, the samples taken from the second supermarket had the highest level of microbial contamination among the three supermarkets, while the samples from the first supermarket had the lowest level of microbial contamination. This experimental finding demonstrated the need for sanitary improvement in the beef retails markets and strict sanitary guideline and implementation of these practices could guarantee consumers' health by consuming raw beefs with the lowest risk of foodborne pathogens.
\end{abstract}

Key words: Microbial contamination, foodborne pathogen, sanitary quality, foodborne pathogenic quality. 